\section{Progress in Synthesis of Monoglycerides for Use in Food and Pharmaceuticals}

Nilesh Ramesh Rarokar, Sunil Menghani, Deweshri Kerzare and Pramod Bhujangrao Khedekar

Department of Pharmaceutical Sciences, Rashtrasant Tukadoji Maharaj Nagpur University, Nagpur, Maharashtra-440033, India

*Corresponding author: Pramod Bhujangrao Khedekar, Department of Pharmaceutical Sciences, Rashtrasant Tukadoji Maharaj Nagpur University, Mahatma Jyotiba Fuley Shaikshanik Parisar, Nagpur, Maharashtra-440033, India, Tel: +91-712-2500324; Fax: +91-712-2500355; E-mail: pbkhedekarudps@gmail.com

Received date: January 15, 2017; Accepted date: July 18, 2017; Published date: July 25, 2017

Copyright: (2017 Rarokar NR, et al. This is an open-access article distributed under the terms of the Creative Commons Attribution License, which permits unrestricted use, distribution, and reproduction in any medium, provided the original author and source are credited.

\begin{abstract}
Glycerides are lipid esters of the glycerol molecule and fatty acids. Their primary function is the storage of energy. Due to its structure and properties, glycerol participates in the formulation or synthesis of many compounds such as food products, cosmetics, pharmaceuticals, liquid detergents. Monoglycerides (MGs) can be formed by both industrial chemical glycerolysis and biological or enzymatic processes. Chemical glycerolysis bring issues of low MGs yield, high operating temperature, formation of undesirable by-products and high energy consumption. On the other hand enzymatic processes have advantages of mild reaction conditions and high purity of MGs. But, several purification steps are required to obtain food or pharmaceutical grade MG, such as neutralization of the reaction media and discoloration followed by expensive molecular distillation. The purpose of this article is to review the main challenges in the synthesis of MGs from triglycerides (TGs) contained in the various fixed oils and application thereof in the food and pharmaceuticals.
\end{abstract}

Keywords: Catalyzation; Glycerolysis; Molecular distillation; Monoglycerides; Solid catalysts

\section{Introduction}

Glycerides are lipid esters of the glycerol molecule and fatty acids and their primary function is storage of energy. During biodiesel synthesis by oil or fat trans-esterification, glycerol is obtained as the main co-product, representing $10 \%$ of the biodiesel production. Therefore, the increasing production of biodiesel around the world generates a glycerol in surplus quantity that is becoming a matter of economic and environmental concern. The dropping of glycerol price has forced the producers to burn or sell glycerol without even refining it. Thus, new applications intended to convert glycerol into value added chemicals is highly desirable not only to improve the economics of biodiesel production but also for ecological factor. Due to its structure and characteristics properties, glycerol is gaining importance in the formulation and synthesis of many compounds such as food products, cosmetics, pharmaceuticals and liquid detergents [1]. Glycerol can also be used in the synthesis of hydrogen [2], liquid fuels [1], fuel additives [3] and chemicals [4,5]. The synthesis of monoglyceride (MG) either by glycerol esterification or trans-esterification, is an attractive option to transform this biomass derived compound into fine chemicals.

The purpose of this article is to review the main challenges in the synthesis of MGs from triglycerides (TGs) contained in the various fixed oils and application thereof in the food and pharmaceuticals. The advancement in synthetic procedures such as traditional synthesis of MGs by chemical process and recent development in commercial technology like glycerolysis, enzymatic synthesis, alcoholysis also been reviewed.

\section{Types of Glycerides}

Glycerides can be subdivided into two categories.
1. The neutral glycerides: these are non-ionic and nonpolar.

2. The phosphoglycerides: these contain a polar region, the phosphoryl group.

Both of these two types of glycerides can be seen as possessing a three carbon "backbone" of the glycerol molecule [6]. Esterification of glycerol with a fatty acid produces a neutral glyceride. Esterification may occur at one, two or all three positions (Figure 1A-C) producing:

- Monoglycerides (monoacylglycerols)

- Diglycerides (diacylglycerols)

- Triglycerides (triacylglycerols)

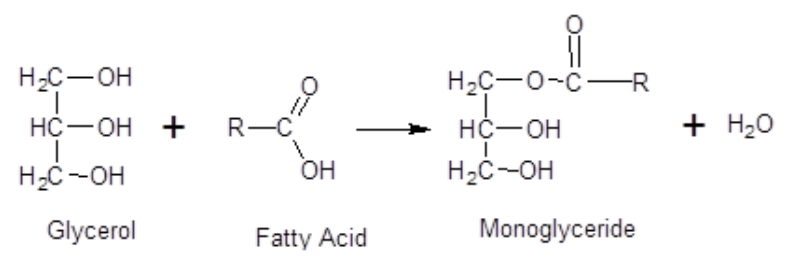

Figure 1A: Synthesis of monoglycerides from fatty acid and glycerol. 


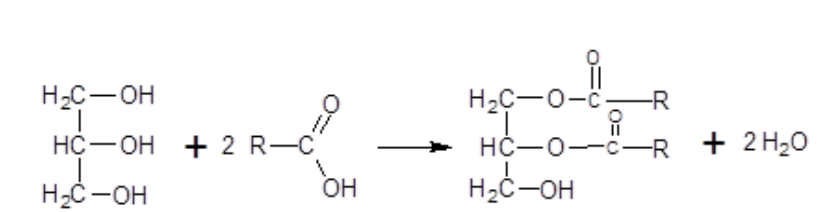

$$
\begin{aligned}
& \text { Glycerol Fatty Acid Diglyceride }
\end{aligned}
$$

Figure 1B: Synthesis of diglycerides from fatty acid and glycerol.

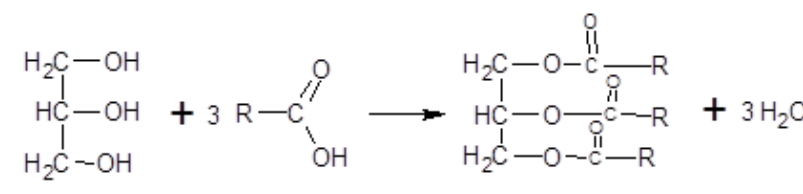

$$
\begin{aligned}
& \text { Glycerol Fatty Acid Triglyceride }
\end{aligned}
$$

Figure 1C: Synthesis of tri-glycerides from fatty acid and glycerol.

\section{Monoglycerides}

This is the most prevalent and important type of glyceride and correctly known as a monoacylglycerol. It constitutes one fatty acid chain covalently bonded to a glycerol molecule through an ester linkage. Based on position of ester bond on glycerol moiety, these are further categorized into:

- 1-Monoacylglycerols and

- 2-Monoacylglycerols

MGs can be formed by both industrial chemical and biological processes while the biochemical synthesis carried out via release of a fatty acid from diacylglycerol through enzymatic action of diacylglycerol lipase or hormone sensitive lipase. They can be broken down by the enzyme known as monoacylglycerol lipase. Mono- and di-glycerides and their derivatives account for about $70 \%$ of this world production, therefore it is considered as the most important group of emulsifiers [6]. Because of their emulsifying properties MGs gaining applications in food, detergent, plasticizer, cosmetics and pharmaceutical formulations [5,7].

\section{Physicochemical Properties}

- $M G$ is an amphiphilic molecule, in which fatty acid chain covalently bonded to glycerol molecule through ester linkage.

- The remarkable mesomorphic behaviour is accounted to their amphiphilic nature. At temperatures above the melting point of the hydrocarbon region (Krafft temperature) and in the presence of water, the hydrocarbon chains transform into a disordered state and water penetrates among the ordered polar groups [6]. If the water content is increased above the swelling limit of the lamellar phase, there will be the formation of a lamellar dispersion.

- The watery phase exists like liposomes consisting of concentric bimolecular shells of MGs alternating with water shells [6].

- When mixed with water and oil, MG exist as self-assembled structures, which can be used as a NDDS, to protect sensitive bioactive substances from degradation, to solubilise drugs, and control the release of active compounds [8].

- Glycerides of unsaturated fatty acids have lower melting points than those of saturated acids with the same number of C-atoms.

- The properties of MGs are dependent on the bonded fatty acid groups [8].

- Unsaturated MGs are more feasible than saturated one in relation to their application.

- Relatively high proportion of unsaturated glycerides present in fixed oil which does not evaporated on warming and remains as a solid, semisolid or liquid state.

\section{Synthesis of Monoglycerides}

There are two main synthetic routes for obtaining MGs: direct esterification of glycerol with fatty acids and trans-esterification of glycerol with fatty acid methyl esters (FAME) (Figure 2). In both routes the commercial processes use homogeneous catalysts. Former method requires an acid catalyst e.g., sulphuric, phosphoric, or organic sulfonic acid $[9,10]$ whereas later case is a basic catalyzed reaction with a strong base such as $\mathrm{KOH}$ or $\mathrm{Ca}(\mathrm{OH})_{2}$ at high temperatures [11]. Glycerolysis of FAME is an interesting route for MG synthesis. Using methyl esters instead of the corresponding fatty acids and glycerol in the preparation of MGs has several advantages. For instance, methyl esters that are prepared from fats by energy preserving fat methanolysis reactions are easily purified and less corrosive. Furthermore, glycerolysis of fatty acids occurs more rapidly than esterification of fatty acids with glycerol [12].

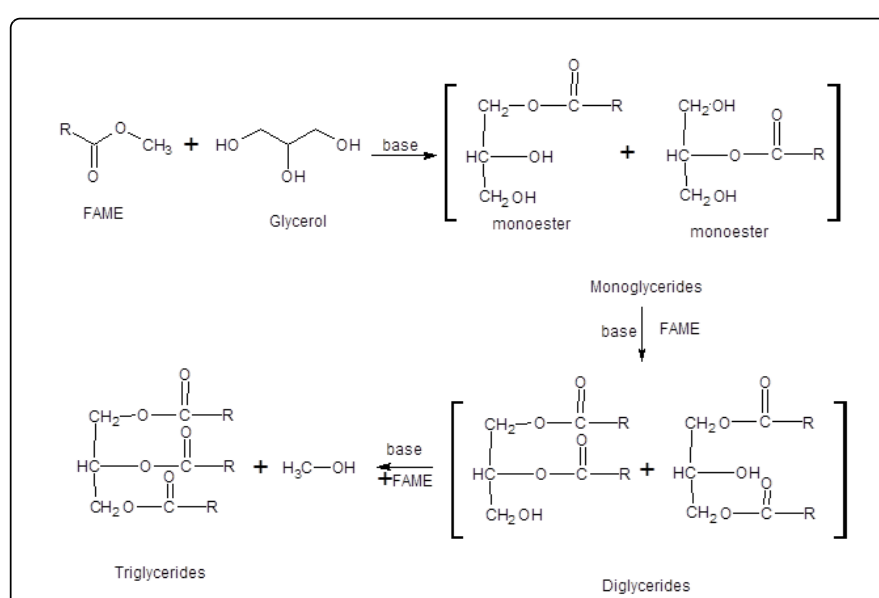

Figure 2: Monoglyceride synthesis via trans-esterification (glycerolysis) of FAME with glycerol and consecutive reactions to diglycerides and triglycerides.

The conventional chemical method to produce MGs involves the glycerolysis of fats and oils at higher temperatures $\left(220-260^{\circ} \mathrm{C}\right)$ and elevated pressure under nitrogen atmosphere while employing inorganic alkaline catalysts. This method compromise with certain major drawbacks includes high-energy consumption, low yield, and poor product quality [13]. Molecular distillation is usually needed for the production of high purity MG $[14,15]$. Moreover, this process produces environmentally undesirable by-products [6]. The product is a mixture containing $35-60 \%$ monoacylglycerols, $35-50 \%$ diacylglycerols, $1-20 \%$ triacylglycerols, $1-10 \%$ free fatty acids, and their alkali metal salts. MGs can be synthesized from glycerol using 
triglycerides (TGs), fatty acids (FA) or fatty acid methyl esters (FAME). However, the process from FAME possesses several advantages, e.g., less corrosive compared than FA, has lower hydrophobic character than TG and exhibits higher miscibility with glycerol; therefore, the process can be carried out at lower temperatures $\left(120-230^{\circ} \mathrm{C}\right)$ than $\mathrm{TG}$ trans-esterification $\left(\approx 260^{\circ} \mathrm{C}\right)$.

There are various processes used for the synthesis of monoglycerides from triglycerides containing oils. Some of those important synthetic processes are discussed herein.

\section{Chemical process}

MGs are the most widely used in the food, pharmaceutical and other industries and also considered to be potentially health beneficial emulsifiers [16,17]. Currently, they are obtained at industrial scale using non-selective inorganic catalysts at high temperatures $\left(200-250^{\circ} \mathrm{C}\right)$, starting with fatty acids, followed by direct esterification or reaction with pure TGs and by inter-esterification with glycerine [18-21]. This results into the low MAG yield, high operating temperature, formation of undesirable by-products and also the high energy consumption.

\section{Drawbacks of chemical process}

These chemically catalyzed processes have several drawbacks, such as;

- The traditional chemical methods involve many reaction steps.

- The generation of dark coloured by-products with an undesirable flavour and low yields (30-40\%); therefore, to concentrate MGs up to more than $90 \%$, purification by molecular distillation is usually required $[18,19]$.

- Chemical glycerolysis is especially not suitable for synthesis of unsaturated MAGs because of instability at high temperatures due to the unsaturated bonds $[20,21]$.

These drawbacks can be overcome by using lipases instead of inorganic catalysts to produce MGs and DGs to avoid unwanted products, can be accomplished at lower temperatures, saves energy and generates light-coloured by-products.

\section{Enzymatic glycerolysis and liquid catalyzation}

Enzymatic processes have advantages of mild reaction conditions and high purity MG yielding method as compared to chemical methods. This approach is assumed to be environmentally friendly. Enzymatic and liquid acid- or liquid base-catalyzed production of MG has been extensively investigated lately [1,7]. However, enzymatic processes are generally difficult to set up, expensive and not much efficient because of enzyme reusability issues. On the other hand, the two main liquid-catalyzed synthesis routes to produce MG from glycerol involve strong mineral acids such as sulphuric and phosphoric acids or strong bases such as $\mathrm{Ca}(\mathrm{OH})_{2}$ and $\mathrm{KOH}$.

Methods of enzymatic synthesis include hydrolysis or alcoholysis, esterification and glycerolysis. Highly stable lipases in organic solvent offers the possibility of employing various approaches to the enzyme catalyzed synthesis, such as selective hydrolysis or alcoholysis using 1,3-regiospecific lipases [22], esterification of glycerol with fatty acids [23] and glycerolysis of fats or oils [24]. When the production of a high degree pure monoglyceride is desired, lipase-catalyzed esterification is the appropriate route. Lipase-catalyzed synthesis of these partial glycerols by the direct esterification of glycerol with fatty acids in different reaction media have been studied and concluded that aqueous-organic two-phase systems [25], microemulsions [26,27] and anhydrous organic solvents [27] as well as the use of solvent-free systems are the best selections [28,29]. Apart from solvent system, proper selection of lipase also contributes to success of the method. Recent studies have suggested that under the optimized conditions, the yield of diolien and 1,3-diolien could be achieved 96.3\% and $97.3 \%$ respectively, which translates to an overall yield of 93.7\% 1,3-diolien and developed as an efficient and promising bioprocess for 1,3-diolien synthesis [30].

Wang and co-workers developed a method to synthesized highly pure diacylglycerol by enzymatic glycerolysis of vegetable oil (soyabean oil). The designed synthesis method offered considerable advantages in production of high purity diacyglycerols and the reusability of the immobilized lipase Novozym 435 was evaluated and confirmed over 15 batches reaction [31].

\section{Advantages of enzymatic glycerolysis}

- The advantages of enzymatic synthesis are higher yields and mild reaction conditions, resulting in products of higher quality and lower energy consumption [15,21].

- Enzyme-catalyzed glycerolysis of MGs is more concerned since it offers a high level of substrate conversion, i.e., 3 moles of $\mathrm{MG}$ could be formed from 1 mole of oil/fat [32].

\section{Drawbacks of enzymatic glycerolysis and liquid catalyzation}

- The drawbacks of the enzymatic methods are low space velocity and a relatively complex work-up of the reaction mixture.

- The process of liquid catalization results into high toxicity, corrosion, and disposal of spent acid or base materials.

- The reaction products contain only $40-60 \% \mathrm{MG}$, the rest being DG and TG.

- Several purification steps are required to obtain food or pharmaceutical grade MG, such as neutralization of the reaction media and discoloration followed by expensive molecular distillation [5,7].

- Another drawback associated with use of homogeneous catalysts is the need for a neutralization step with the formation of soaps and a high salt content.

\section{Two stage enzymatic process}

The synthesis of high oleic glycerol monooleate by enzymatic glycerolysis of high oleic sunflower oil, using Novozyme 435 as the biocatalyst, in a binary solvent mixture of tert-butanol (TB) and tertpentanol (TP) in the ratio of 80:20 v/v, at a lab scale has been studied. A yield of $75.31 \% \mathrm{MGs}$ has been achieved at the first stage. A yield of 93.3\% glycerol monooleate was finally reached after further purification at the second stage. TB can be used in the production of MG with a high conversion rate, stable enzyme activity, good ability in dissolving glycerol and oils, and takes a lower cost. However, the melting point of $\mathrm{TB}$ is relatively high $\left(25.69^{\circ} \mathrm{C}\right)$ and the temperature difference between the melting and boiling points of TB is about $57^{\circ} \mathrm{C}$, were not adequate to avoid the practical problems with crystallization [33]. Thus, an efficient binary solvent mixture system, TB/TP, was employed to overcome this problem. 


\section{Synthesis by solid catalyzation}

The synthesis of MGs by glycerolysis of methyl-oleate on acid-base solid catalysts is an alternative method to the current commercial technology that uses liquid base catalysts. The reaction conditions such as catalyst particle size and stirring rate required for operating the four-phase semi-continuous reactor are taken into consideration which one is under a kinetically controlled regime. Then the optimization of the reaction parameters for achieving high $M G$ yields can be performed using $\mathrm{MgO}$ [25]. The use of high reaction temperatures $\left(220-250^{\circ} \mathrm{C}\right)$, glycerol/methyl-oleate molar ratios between 2 and 6 , as well as catalyst/reactant ratios of about $30 \mathrm{~g} / \mathrm{mol}$, glycerolysis of methyl-oleate yields up to $77 \%$ monoglycerides in $2 \mathrm{~h}$. The yield obtained during this process is a much higher value than the liquid base-catalyzed homogeneous process which is about $40-60 \%$.

MgO-based catalyzation: The monoglyceride synthesis from methyl-oleate and glycerol is efficiently catalyzed on $\mathrm{MgO}$ and $\mathrm{Li}-$ promoted $\mathrm{MgO}$ catalysts. Monoglyceride yields of up to $73 \%$ are obtained on $\mathrm{MgO}$ and low loading Li-promoted $\mathrm{MgO}(\leq 0.3 \mathrm{wt} \% \mathrm{Li}$ ) at $220^{\circ} \mathrm{C}$ in excess glycerol. Monoglyceride formation is promoted on strong base sites and thus the intrinsic initial monoglyceride formation rate increases with increase in the $\mathrm{Li}$ content. Li-promoted $\mathrm{MgO}$ catalysts show less affinity for glycerol adsorption because of more hydrophobic surface than that of $\mathrm{MgO}$. A weaker glycerol adsorption on the catalyst surface would enable monoglyceride re-adsorption and its get converted to diglycerides [34].

Heterogeneous catalyzation: The heterogeneously catalyzed monoglyceride synthesis is a four-phase reaction (Figure 3). This can be conducted in kinetic control regime in which appropriate operative conditions are used, namely: relatively high stirring rates (500-700 $\mathrm{rpm}$ ) and mean catalyst particle sizes of up to $250 \mu \mathrm{m}$.

Advantages of solid catalyzation: The use of solid catalysts for monoglyceride synthesis, presents not only the known environmental and practical advantages but also provides the opportunity to increase their yield by developing a catalyst with tuneable structural, surface acid-base and textural properties specifically designed to promote the reaction.

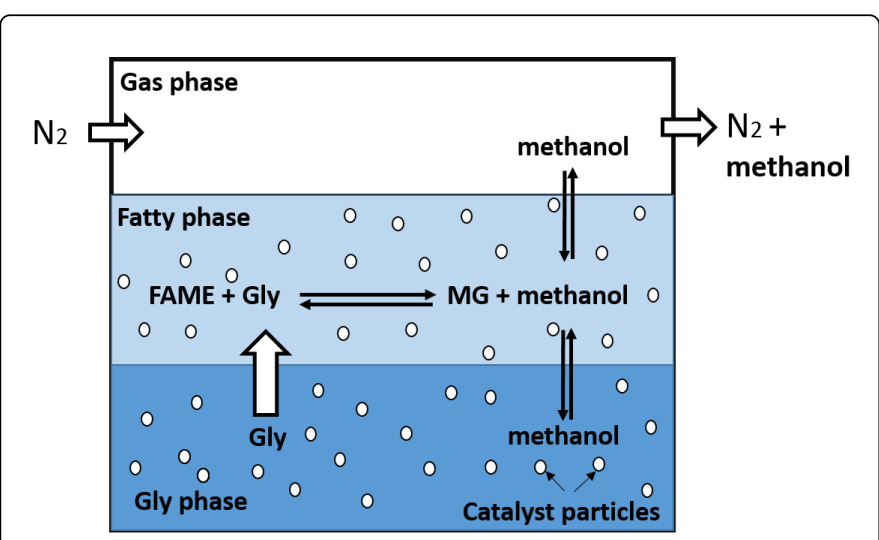

Figure 3: Four-phase reactor for the heterogeneously catalyzed monoglyceride synthesis.

\section{Alcoholysis}

Triglycerides are convenient starting materials for preparation of 2monoglycerides by hydrolysis or alcoholysis. The mechanism for this process is believed to be a ping-pong-bi-bi mechanism involving an acyl enzyme complex as intermediate. The first reaction step is deacylation of the triglyceride and acylation of the enzyme. This acyl enzyme is deacylated by nucleophilic attack by water (hydrolysis) or an alcohol (alcoholysis) to produce free fatty acid or fatty acid ester, respectively. In the next step the diglyceride undergoes the same process and 2-monoglyceride is produced. Both hydrolysis [22] and alcoholysis [35,36] have been described for preparation of 2monoglycerides.

\section{Advantages of alcoholysis:}

- A benefit of this method is that it results in isomerically pure 2monoglyceride.

- An attractive route to pure regio-isomers is to use 1,3- specific lipases as catalysts for synthesis either from glycerol and a fatty acyl donor by hydrolysis or alcoholysis of a triglyceride.

\section{Drawbacks of alcoholysis:}

- In practice several reaction parameters have to be optimized to obtained high yields of the desired product.

- Special precautions have to be taken to avoid acyl migration, which otherwise will reduce the yield.

\section{Purification of Monoglyceride}

The enzymatic glycerolysis for MG production leads to mixtures of monoglycerides, diglycerides, triglycerides and some glycerol. However, as well known the pure MG has much better emulsifying properties than a mixture of different glycerols, the purification of the glycerolysis products by molecular distillation is therefore valuable for achievement of highly pure MG $[37,38]$.

\section{Molecular distillation}

The products from the enzymatic glycerolysis of oils contain glycerol, free fatty acids, monoglycerides, diaglycerides and some triglycerides. Molecular distillation is therefore necessary to obtain a highly pure MG after the glycerolysis reaction [38]. Although a relatively high yield of MG can be produced by enzymatic glycerolysis, molecular distillation is a good option and necessary for producing highly pure MAG. Molecular distillation is a vacuum distillation in which the molecules (distillates) escaping from the warm liquid to reach the cooled surface of the condenser before colliding with other molecules (residues) and consequently returning to the liquid. Major factors that might affect the separation efficiency include evaporation temperature, operating pressure, feed flow rate, condenser temperature and rotational speed [39]. The operating pressure could hardly be fixed at a constant value, the condenser temperature and rotational speed had little influence on the separation, and the feed flow rate normally matched the production capacity of the equipment.

To obtain a highly pure monoglyceride, the molecular distillation was carried out in two steps. The first step was set to remove the glycerol and fatty acids. The distillation is operated under the evaporating temperature of $120^{\circ} \mathrm{C}, 130^{\circ} \mathrm{C}, 140^{\circ} \mathrm{C}$ and $150^{\circ} \mathrm{C}$, with the other fixed conditions: system pressure (1-5 Pa), the rotational speed (200 rpm), condenser temperature $\left(40^{\circ} \mathrm{C}\right)$, feed temperature $\left(100^{\circ} \mathrm{C}\right)$ and feed flow rate $(1.5 \mathrm{~mL} / \mathrm{min})$. The second step is aimed to gather 
the MG from the residue left from the first step distillation, under the evaporating temperature of $160^{\circ} \mathrm{C}, 170^{\circ} \mathrm{C}, 180^{\circ} \mathrm{C}$ and $190^{\circ} \mathrm{C}$.

\section{Uses and Applications of Glycerides}

1. The use of mono- and diacylglycerols as non-ionic emulsifiers in the food and pharmaceutical industries and as synthetic chemical intermediates has been a growing research area in recent years $[14,40]$. Furthermore, they have a generally recognized as safe status, which contributes to their larger application.

2. Mono- and diglycerides are consumed at an annual level of $85,000,000 \mathrm{~kg}$ in the United States, corresponding roughly to $70 \%$ of the total emulsifiers used in the food industry $[28,41]$.

3. The antimicrobial activities of particular types of monoglycerides such as monolaurin, monomyristin, monolinolein, and monolinolenin have also been reported [42].

4. Monoglycerides, the glycerol monoesters of fatty acids, are molecules consisting of a hydrophilic head and a hydrophobic tail that helps hydrophilic and lipophilic substances to mix together. Therefore, they can be used in food, detergent, plasticizer, cosmetic and pharmaceutical formulations [5,7]. MGs can be synthesized from glycerol using TG, FA or FAME. However, the process from FAME has several advantages, e.g., FAME is less corrosive than FA, has lower hydrophobic character than TG and exhibits higher miscibility with glycerol; therefore, the process can be carried out at lower temperatures $\left(120-230^{\circ} \mathrm{C}\right)$ than $\mathrm{TG}$ trans-esterification $\left(\approx 260^{\circ} \mathrm{C}\right)$.

5. Glyceryle monooleaate has many uses including preventing cardiovascular disorders by donating unsaturated fatty acids $[38,43,44]$.

6. Mono- and Diglycerides are commonly added to commercial food products in small quantities. They helps to mix ingredients such as oil and water that would not otherwise blend well. The commercial source may be either animal (cow- or pig-derived) or vegetable, and they may be synthetically made as well. They are often found in bakery products, beverages, ice cream, chewing gum, shortening, whipped toppings, margarine, and confections.

7. Approximately $60 \%$ of all monoglycerides are used in bakery, $40 \%$ in bread and $20 \%$ in sponge cakes and cakes [45]. In these applications, monoglycerides are added as powder, gel or part of a shortening [46-50].

\section{Conclusion}

Glyceride is used in food and pharmaceuticals as an emulsifier because of having hydrophilic head and lipophilic tail. Synthesis of glyceride is becoming a need of pharmaceuticals, so to fulfil this need efficient synthetic method is one of the important aspects for the commercialization of glyceride. Commercial method should be efficient, high yielding and should be carried out at lower temperature also devoid of undesirable by-product. But traditional commercial production of glyceride had done by chemical glycerolysis which bring issues of low MG yield, high operating temperature and required maximum reaction steps. Therefore, researcher contributes to developed efficient synthetic procedure which is devoid of all these difficulties faced during chemical glycerolysis.

Lipase catalyzation and enzymatic glycerolysis overcome the drawbacks of chemical process. Enzymatic synthesis of monoglycerides is environmentally friendly approach and having advantages of higher yields and mild reaction conditions, resulting in product of higher quality moreover lower energy consumption. Although, enzymatic processes are difficult to set up, expensive and not very resourceful because of enzyme reusability issues hence it is necessary to undertake more efforts to solve these problems with synthesis of monoglycerides.

\section{Conflicts of Interest}

All contributing authors declare no conflicts of interest.

\section{References}

1. Corma A, Huber GW, Sauvanaud L, O’Connor P (2007) Processing biomass-derived oxygenates in the oil refinery: catalytic cracking (FCC) reaction pathways and role of catalyst. J Catal 247: 307-327.

2. Shabaker JW, Huber GW, Dumesic JA (2004) Aqueous-phase reforming of oxygenated hydrocarbons over Sn-modified Ni catalysts. J Catal 222: 180-191.

3. Karinen RS, Krause AOI (2006) New biocomponents from glycerol. Appl Catal A: Gen 306:128-133.

4. Corma A, Iborra S, Velty A (2007) Chemical routes for the transformation of biomass into chemicals. Chem Rev 107: 2411-2502.

5. Zheng Y, Chen X, Shen Y (2008) Commodity chemicals derived from glycerol, an important biorefinery feedstock. Chem Rev 108: 5253-5277.

6. Krog NJ (1997) Food emulsifiers and their chemical and physical properties. In Food Emulsion; Friberg, S E, Larsson, K, editors. Marcel Dekker: NY p: 141-188.

7. Corma A, Hamid SBA, Iborra S, Velty A (2005) Lewis and Bronsted basic active siteson solid catalysts and their role in the synthesis of monoglycerides. J Catal 234: 340-347.

8. Damstrup ML, Jensen T, Sparso FV, Kiil SZ, Jensen AD, et al. (2006) Production of heat-sensitive monoacylglycerols by enzymatic glycerolysis in tert-pentanol: process optimization by response surface methodology. J Am Oil Chem Soc 83: 27-33.

9. Devinat G, Coustille JL (1983) Re-esterification on a pilot scale of the fatty acids of Colza and soybean. Rev Fran Corps Gras 30: 463-468.

10. Swern D (1979) Industrial Oil and Fats Products. Wiley, New York 1: 497-601.

11. Sonntag NOV (1982) Glycerolysis of fats and methylesters-Status, review and critique. J Am Oil Chem Soc 59: 795A-802A.

12. Gross AT, Feuge RO (1949) Modification of vegetable oils. VIII. Conversion of monoesters of peanut oil fatty acids to triglycerides. J Am Oil Chem Soc 26: 704 .

13. Berger M, Schneider MP (1992) Enzymatic esterification of glycerol II. Lipase-catalyzed synthesis of regioisomerically pure 1(3) - racmonoacylglycerols. J Am Oil Chem Soc 69: 961-965.

14. Freitas L, Bueno T, Perez VH, Castro HF (2008) Monoglycerides: production by enzymatic route and applications. Quim Nova 31: 1514-1521.

15. Bornscheuer UT (1995) Lipase-catalyzed syntheses of monoacylglycerols. Enzyme Microb Technol 17: 578-586.

16. Sagalowicz L, Leser ME, Watzke HJ, Michel M (2006) Monoglyceride selfassembly structures as delivery vehicles. Trends Food Sci Technol 17: 204-214.

17. Ferreira-Dias S, Correia AC, Fonseca MMR (2003) Response surface modelling of glycerolysis catalysed by Candida rugosa lipase immobilized in different polyurethane foams for the production of partial glycerides. J Mol Catal B: Enzym 21: 71-80.

18. Kaewthong W, Sirisansaneeyakul S, Prasertsan P, H-Kittikun A (2005) Continuous production of monoacylglycerols by glycerolysis of palm oil with immobilized lipase. Process Biochem 40: 1525-1530.

19. Kaewthong W, H-Kittikun A (2004) Glycerolysis of palm olein by immobilized lipase PS in organic solvents. Enzyme Microb Technol 35: 218-222. 
Citation: Rarokar NR, Menghani S, Kerzare D, Khedekar PB (2017) Progress in Synthesis of Monoglycerides for Use in Food and Pharmaceuticals. J Exp Food Chem 3: 128. doi:10.4172/2472-0542.1000128

Page 6 of 6

20. Yesiloglu Y (2004) Immobilized lipase-catalyzed ethanolysis of sunflower oil. J Am Oil Chem Soc 81: 157-160.

21. Ferreira-Dias S, Correia AC, Baptista FO, da Fonseca MMR (2001) Contribution of response surface design to the development of glycerolysis systems catalyzed by commercial immobilized lipases. J Molecular Catalysis B: Enzymatic 11: 699-711.

22. Holmberg K, Osterberg E (1988) Enzymatic preparation of monoglycerides in microemulsion. J Am- Oil Chem- Soc 65: 1544-1548.

23. Akoh CC, Cooper C, Nwosu CV (1992) Lipase G-catalyzed synthesis of monoglycerides in organic solvent and analysis by HPLC. J Am Oil Chem Soc 69: 257-260.

24. Cheirsilp B, Jeamjounkhaw P, H-Kittikun A (2009) Optimizing an alginate immobilized lipase for monoacylglycerol production by the glycerolysis reaction. J Mol Catal B: Enzyme 59: 206-211.

25. Ferretti CA, Soldano A, Apesteguia CR, Di Cosimo JI (2010) Monoglyceride synthesis by glycerolysis of methyl oleate on solid acidbase catalysts. Chemical Engineering J 161: 346-354.

26. Van Der Padt A, Keurentjes JTF, Sewalt JJW, Van Dam EM, Van Dorp LJ, et al. (1992) Enzymatic Synthesis of Monoglycerides in a Membrane Bioreactor with an In-line Absorption Column. J Am Oil Chem Soc 69: 748-754.

27. Castillo E, Dossat V, Marty A, Condoret JS, Combes D (1997) The role of silica gel in lipase-catalyzed esterification reactions of highpolar substrates. J Am Oil Chem Soc 74: 77-85.

28. Langone MAP, De Abreu ME, Rezende MJC, Sant'Anna Jr GL (2002) Enzymatic synthesis of medium chain monoglycerides in a solvent -free system. Appl Biochem Boitechnol 98: 987-996.

29. Freitas L, Perez VH, Santos JC, de Castro HF (2007) Enzymatic synthesis of glyceride esters in solvent-free system: Influence of the molar ratio. Brazil Chem Soc 18: 1360-1366.

30. Duan Zhang-Qun, Du Wei, Liu De-Hua (2013) Improved synthesis of 1.3-diolein by Novozym 435-mediated esterification of monoolein with oleic acid. J Mol Catal B Enzym 89: 1-5.

31. Wang W, Li T, Ning Z, Wang Y, Yang B, et al. (2011) Production of extremely pure diacylglycerol from soybean oil by lipase-catalyzed Glycerolysis. Enzyme and Microbial Technology 49: 192-196.

32. Yang T, Rebsdorf M, Engerlrud U, Xu X (2005) Monoacylglycerol synthesis via enzymatic glycerolysis using a simple and efficient reaction system. J Food Lipids 12: 299-312.

33. Pawongrat R, Xu X, H-Kittikun A (2008) Physico-enzymatic production of monoacylglycerols enriched with very-long-chain polyunsaturated fatty acids. J Sci Food Agric 88: 256-62.

34. Ferretti CA, Apesteguia CR, Di Cosimo JI (2011) MgO-based catalysts for monoglyceride synthesis from methyl oleate and glycerol: Effect of Li promotion. App Cat A: Gen 399: 146-153.
35. Zuyi L, Ward OP (1993) Lipase-catalyzed alcoholysis to concentrate the o-3-polyunsaturated fatty acids of cod liver oil. Enzyme Microb Technol 15: 601-606.

36. Rarokar NR, Saoji SD, Raut NA, Taksande JB, Khedekar PB, et al. (2015) Nanostructured Cubosomes in a Thermoresponsive Depot System: An Alternative Approach for the Controlled Delivery of Docetaxel. AAPS PharmSciTech 17: 436-445.

37. Ghamgui H, Miled N, Rebai A, Karra-chaabouni M, Gargouri Y (2006) Production of mono-olein by immobilized Staphylococcus simulans lipase in a solvent-free system: optimization by response surface methodology. Enzyme Microb Technol 39: 717-23.

38. Perez-Pariente J, Diaz I, Mohino F, Sastre E (2003) Selective synthesis of fatty monoglycerides by using functionalised mesoporous catalysts. Appl Catal A 254: 173-88.

39. Fregolente LV, Fregolente PBL, Chicuta AM, Batistella CB, Maciel Filho $R$, et al. (2007) Effect of operating conditions on the concentration of monoglycerides using molecular distillation. Chem Eng Res Des 85:1524-1528

40. Trivedi R, Singh RP (2005) Modification of oils and fats to produce structured lipids. J Oleo Sci 54: 423-430.

41. Cyberlipid Center (2009) Monoacylglycerols.

42. Chaibi A, Lahsen HA, Busta FF (1996) Inhibition of bacterial spores and vegetative cells by glycerides. J Food Prot 59: 716-722.

43. Zhang Z, Goff HD (2005) On fat destabilization and composition of the air interface in ice cream containing saturated and unsaturated monoglyceride. Int Dairy J 15: 495-500.

44. Damstrup ML, Jensen T, Sparso FV, Kiil SZ, Jensen AD, et al. (2005) Solvent optimization for efficient enzymatic monoacylglycerol production based on a glycerolysis reaction. J Am Oil Chem Soc 82: $559-64$.

45. Moonen H, Bas H (2004) Mono- and diglycerides. Whitehurst RJ, editor. Emulsifiers in food technology. Oxford: Blackwell Publishing p. 40-58.

46. Henry C (1995) Monoglycerides-The Universal Emulsifier. Cereal Foods World 40: 734-738.

47. Pawongrat R, Xu X, H-Kittikun A (2007) Synthesis of monoacylglycerol rich in polyunsaturated fatty acids from tuna oil with immobilized lipase. AK Food Chem 104: 251-258.

48. Zeng F, Yang B, Wang Y, Wang W, Ning Z, et al. (2010) Enzymatic production of monoacylglycerols with camellia oil by the glycerolysis reaction. J Am Oil Chem Soc 87: 531-537.

49. Friberg E, Larsson K (2004) Food emulsions. New York: Marcel Dekker p: 112-118.

50. Jerome F, Pouilloux Y, Barrault J (2008) Rational design of solid catalysts for the selective use of glycerol as a natural organic building block. Chem Sus Chem 1: 586-613. 